\title{
Are Routine Manual Systems Genuine Information Systems?
}

\author{
Reeva Lederman \\ Department of Information Systems, University of Melbourne \\ email: reevamı@unimelb.edu.au \\ Robert Johnston \\ Department of Information Systems, University of Melbourne \\ email: r.johnston@dis.unimelb.edu.au
}

\begin{abstract}
The information systems literature describes many systems - both computerised and manual - that are commonly accepted to be information systems (IS). However, there is also a group of systems found in the literature, which will be called routine, manual systems, that appear to provide participants with cues for action but which do not have the hallmarks of traditional information systems. These systems contain elements that are both stored and manipulated in ways that are different to what is observed in traditional data processing. This paper asks whether or not these systems in fact share common characteristics with traditional IS and which would allow us to call them information systems. It is found that, in using terminology from general systems theory and the semiotics literature, it is possible to find common ground between these systems and traditional IS, thus making the term 'information system' a legitimate label for such systems. Answering this question is an important first stage in a larger research project that examines what makes routine, manual systems function effectively.
\end{abstract}

\section{Introduction}

Information systems can be computerised or manual, with many manual information systems such as paper ledgers or Kalamazoo accounting systems being noted in the literature (Benson and Standing, 2002; Boddy et al., 2005; Land, 1987; Stair and Reynolds, 2003). However, examples of manual systems given in the literature are generally of systems where written data is stored on paper and there is a relatively simple translation to a computerised model (Checkland and Howell, 1998; Land, 1987). Descriptions of systems in the literature and also real world experience suggests, however, that there is a category of systems whose members support the performance of manual work 
but, because they do not always produce paper to file, or appear to store data in a conventional way, are not seen as information systems and do not fit well with traditional definitions of an information system. In these systems, tasks are completed manually through practiced routines and there is limited reliance on information stored in, and retrieved from, either fixed computerised databases or paper based files. These manual systems may include some paper artifacts (cards or tokens, rather than files) or have physical components often using tools such as whiteboards (Schmidt and Simone, 1996), cards or coloured magnets (Lederman et al., 2003; Mackay, 1999; Wong, 2000) as information resources. While there may be some written information on these artifacts, they do not function as traditional data stores. Instead, the meaning of these artifacts is contained, for example, in their colour or placement. Included among the socio-technical systems exhibiting these traits are some hospital scheduling systems, air traffic control systems and systems in small manufacturing concerns.

These manual systems support work that is relatively complex but largely repetitive and routine and many of the human activities in these systems appear to be performed in a largely non-cognitive way. They comprise forms of activity where participants use their tacit knowledge of work practices and various cues perceived directly from the work environment to routinely perform manual tasks. In these systems actors use cues embedded in the physical components of the system to deduce information on how to act to complete goals. For example, a magnet of a particular colour on a whiteboard might promote a particular response. While such systems have been discussed previously, the information systems literature does not consider to any significant degree how these manual artifacts provide signals or cues for behaviour, how system participants respond to these cues, or the role that manual artifacts play in providing information for routine (non-cognitive) action. Particularly, previous research does not focus on the extent to which these systems can be viewed as genuine information systems rather than simply as discrete tools or aides memoire. In this paper, such systems will be termed routine, manual systems.

This paper examines the legitimacy of regarding these routine, manual systems as information systems. Information in these systems is not defined in terms of our traditional understanding of it as processed data so conventional definitions of IS do not appear to suit these systems. However, this paper claims they can still rightfully be called information systems. Because these systems do not store or process data in ways commonly documented in the IS literature we seek a way of explaining how these systems conform to a definition of information systems that is broader than that commonly found in the IS literature.

The method we use is to firstly examine traditional definitions of the term 'information system'. From these definitions we extract four general concepts that we use to form the basis of a new definition: fact, transformation, signal 
and action. Then we present four example systems. The first is a conventional information system and is presented as an illustration of the type of system commonly regarded as an information system. This provides a basis for understanding why it may be difficult to also perceive a routine, manual system as an IS because, prima facie, they appear to be very different. However, we then describe three routine, manual systems and consider how the elements in our new definition of an information system appear in all three of these systems. Then we reflect, using the literature and our own observations, on the answer to the question: Are routine, manual systems genuine information systems?

We find that the three routine, manual systems form a class with common characteristics that can conform to a broader definition of information systems than is currently commonly used. In answering the question of whether or not they are information systems we stand to gain an important insight into their relationship to traditional information systems as well how they provide a source of information to their users in informing action.

\section{Definitions of information systems}

The information systems literature recognises that the term 'information system' is a broad one and throws up a number of different definitions. These definitions fall loosely into two categories: those that have computerised technology artifacts at the centre of the system and those where systems are not necessarily computer technology dependent. Definitions in the former category typically describe an information system as being 'any organised combination of people, hardware, software, communications networks and data resources that collects, transforms and disseminates information in an organisation' (O'Brien, 2003) or 'people, data/information, procedures, software, hardware, communications' (Benson and Standing, 2002). Those who subscribe to the second position include similar elements but without the idea of technology being an essential component. Stair and Reynolds (2003), for example, define an IS as a 'set of interrelated components that collect, manipulate and disseminate data and information to provide a feedback mechanism to meet an objective'. Similarly, according to Laudon and Laudon (2006), an IS is 'to support decision making and control in an organisation'. Most other approaches to information systems theory propose that all information systems exhibit certain basic features, notably input, processing (which produces output) and feedback. The input stage involves the gathering and capturing of raw data' (Stair and Reynolds, 2003), the output involves 'producing useful information' (Stair and Reynolds, 2003) from the processed input, and processing involves, 'converting or transforming data into useful outputs' (Stair and Reynolds, 2003). Finally, feedback 'is output that is used to make changes to input or processing activities' (Stair and Reynolds, 2003). In this way of thinking, a system that includes the interrelated components that perform these tasks is perceived as an information system. A common view 
also adds the idea of self containment in that users work with the system but without direct utilisation of the real world to which the system refers. Rather, they work through a model or abstract representation of the real world (Wand and Weber, 1995). So, for example a system participant can make a decision about action through reference to an inventory database and does not need to look at the stock on the shelf. Within the literature there are also definitions that stress the importance of overall goals and define information systems as systems that provide the impetus for activity (e.g. Goldkuhl and Agerfalk, 1988).

In comparing different types of systems such as traditional computerised information systems and routine, manual systems, implementation details are necessarily different. Consequently, in examining these definitions, we argue that it is valid to ignore those differences or variations that are concerned with implementation. However, four essential concepts remain common to other definitions: input and output, processing (which produces the output) and feedback.

Data inputs are the facts that are gathered and captured in the system. There are many definitions of data in the literature but they are all essentially about the projection, or communication of facts. As examples, data has been said to be 'facts, concepts or derivatives in a form that can be communicated and interpreted' (Galland, 1982) and a 'representation of facts, concepts or instructions in a formalised manner suitable for communication' (Hicks, 1993). Other definitions also include the idea of facts being available for processing (Laudon and Laudon, 2006; Maddison, 1989; Martin and Powell, 1992).

Processing is often considered to be the way data is manipulated, developed or built upon in some way that transforms it to create meaningful information. This is what is contained in the idea of a system itself. Systems theory, an umbrella theory within which information systems theory fits, considers the idea of transformation, which describes the structure of change in natural systems (Land, 1973). Land uses the term 'transformation' to describe how participants in a system negotiate meaning. Faced with signals from their environment, they define and redefine what to do next, repeating successful approaches. Thus, transformation incorporates the notion of processing.

When raw facts are transformed by system processing, output is produced that signals or communicates to participants in the system. Essentially, what defines output in its role as an information systems component is its indicative status, that it signals or projects itself to be acted upon in some way that has value to systems participants. It is the output signalling to users that leads to action. That is, participants react to processed facts and take action for as long as this approach is perceived to be goal attaining.

Feedback occurs when a user responds to the output in such a way that the system input is altered. In traditional information systems this may involve 
deliberation. In routine, manual systems, where there is a reactive response to the output, feedback can ensue without the cognitive activity that deliberation entails. Rather a routine response occurs, which has been learnt from earlier experiences. Either way the output triggers a response in the system participant as a guide and precursor to the feedback activity.

Where there is action it can be presumed that it has resulted as a response to output. It is this action and its effects on system inputs that is significant and keeps the system functioning. So while feedback is the traditional term used its significance in a system results from the action it promotes. The primacy of action in information system is reinforced within semiotics where it is claimed that 'Information systems should be conceived as ... systems intended for action' (Goldkuhl and Agerfalk, 2000). Information systems are also seen to 'exist to support directly those taking the action which results from the formed intentions' (Checkland and Howell, 1998).

This focus on 'those taking the action' is an important element of feedback in an information system. It is suggested that information systems have a 'social dimension' with problems they try to solve being 'people centred' and involving human participation (Benson and Standing, 2002). Also, many definitions of information systems include people and the procedures followed by people, as essential components (Benson and Standing, 2002; Boddy et al., 2005; Stair and Reynolds, 2003). This involvement of people in information systems feedback and activity is crucial.

In general systems theory, all systems include input, processing output and feedback, which creates a relatedness between the parts (von Bertalanffy, 1972; Donde and Huber, 1987). Complex systems such as control systems (for example a thermostat) include these elements. These systems are not, however, regarded as information systems since they do not involve a human or intentional agent who recognises the informational value of the output. In the systems literature there is much discussion of control systems, such as the flyball governor, a system developed in the late 18th century to automatically maintain steam engine speed despite changes in loads and steam supply. This system involves two balls connected to a shaft. The balls rotate in response to the steam supply, causing it to cut off the steam with increased speed and to open the valve as the shaft velocity slows. While this is an example of a system with input, processing producing output, and feedback, it is not an information system without a user to recognise the informational value of changes in the steam supply. Information systems provide information to someone or something; they are not just self-operating control mechanisms. In an information system, human involvement is evident. In traditional information systems the distinction between systems in general and information systems is more obvious because in the latter the informational aspects are separated off into the computer, which provides output 
reports or summaries or calculations for the user to respond to. In routine, manual systems many of the artifacts in these systems (such as magnets on a whiteboard) are not obviously sources of output information until they are placed in a certain way or set in a particular physical context. In these contexts, participants perceive the informational value of the artifacts and make a response to this value. This response requires some human perception of information content. Even where the action is routinised, it will have eventuated from a routine learnt through an earlier process where information was provided that imbued the routine with value for the human participant.

Considering all of these issues, we propose that, in deciding whether or not a system is an information system, the following test should be applied:

- Does it provide facts for the system to manipulate? These facts may be values in a data file or they might be the colours of magnets or the placement of flight strips on a table. A fact is an element that avails itself for transformation.

- Does it exhibit some sort of transformative activity? That is, does it take up the facts and manipulate them in some way that changes the state of the system?

- Does this transformation result in a signal for a system participant to react to? This signal might be a value in a table or a change in the arrangement of an ambulance card in an ambulance allocator's box. A signal is an indicator that presents itself for action.

- Is it a system where action results (through traditional feedback by users or some other type of response) leading to the fulfilment of goals?

In deciding whether or not routine, manual systems are information systems, through examining them alongside traditional systems, we extract examples of elements from both types systems to populate Table 1 below. In this table, the four common elements - fact, transformation, signal, and action - that we claim to be characteristic of all information systems, are provided in the second row. In the rest of this paper, traditional and routine manual systems will be examined in order to populate rows four and five, which are those aspects of the two systems that manifest themselves as facts, transformation, signals, and action. Row five will contain examples of this manifestation as they are uncovered.

\begin{tabular}{|c|c|c|c|c|c|c|c|c|}
\hline \multicolumn{9}{|c|}{ All information systems } \\
\hline & \multicolumn{2}{|l|}{ Fact } & \multicolumn{2}{|c|}{ Transformation } & \multicolumn{2}{|l|}{ Signal } & \multicolumn{2}{|l|}{ Action } \\
\hline & Traditional & Routine & Traditional & Routine & Traditional & Routine & Traditional & Routine \\
\hline & $?$ & $?$ & $?$ & $?$ & $?$ & $?$ & $?$ & $?$ \\
\hline Examples & $?$ & $?$ & $?$ & $?$ & $?$ & $?$ & $?$ & $?$ \\
\hline
\end{tabular}

Table 1: Elements in all information systems 


\section{Descriptions of systems}

In this section four different systems will be described. The first is a conventional information system and the remaining three, routine manual systems. The nature of data processing and feedback in traditional systems will be examined after the first system is described and again for the three routine, manual systems after they are described.

\section{Causeway Cash Receipts System: a traditional information system}

The literature records many traditional systems, both computerised and manual (or a combination of both), that are universally considered to be information systems. One such system, used to process cash received from credit sales (Gelinas and Sutton, 2002), is described in detail below. This system typifies a widely used process for recording cash receipts:

Customers send checks (sic) and remittance advice to Causeway. The mailroom clerk at Causeway endorses the checks and writes the amount paid and the check number on the remittance advice. Periodically, the mail room clerk prepares a batch total of the remittance advices and sends the batch of remittance advices to accounts receivable, along with a copy of the batch total. At the same time, the clerk sends the corresponding batch of checks to the cashier.

In accounts receivable, the clerk enters the batch into an online terminal by keying the batch total, the customer number, the invoice number, the amount paid and the check number. After verifying that the invoice is open and the correct amount is being paid, the computer updates the accounts receivable master data. If there are any discrepancies, the clerk is notified. At the end of each batch (or at the end of the day) the computer prints a deposit slip in duplicate on the terminal in the cashier's office. The cashier compares the deposit slip to the corresponding batch of checks and then takes the deposit to the bank.

As they are entered, the check number and the amount paid for each receipt are logged on disk. The event data is used to create a cash receipts listing at the end of each day. A summary of customer accounts paid that day is also printed at this time. The accounts receivable clerk compares these reports to the remittance advices and batch totals and sends the total of the cash receipts to the general ledger office (Gelinas and Sutton, 2002).

\section{Qualities of traditional systems}

The common, defining characteristics of systems such as the one above have been distilled from observation and presented in previous work (Lederman et 
al., 2003). The features of such systems are those that clearly exhibit the hallmarks of the classical definitions of information systems listed earlier: systems that collect data and process it in conventional ways. Data in these systems has the following qualities:

- Firstly, in such systems data is represented in symbol/object form, where symbols stored in a table correspond to objects in the real world, generally shown as records within fields, and indicate or signal potential manipulations that can be done in the real world. In a system such as Causeway, a table of customers would exist where a customer number and description of a customer forms a symbolic representation of a real customer that exists in the world and that can, for example, be given a new credit rating or a new account balance.

- The representation of data is persistent. That is, such systems display stable data structures. This is seen in Causeway where there are fixed fields with stable meanings, and multiple tables each with fixed record structures. This leads to data being processed in a conventional way where records are transformed but a stable structure remains.

- A third feature relates to the nature of processing. Users in such systems use these stable representations to determine the state of the world and then select the appropriate action. In Causeway, for example, a user might find a credit limit in a table and make a decision about allowing a customer credit. Change then occurs in the customer record as it is transformed to a new state.

Processing proceeds without significant consideration of the physical and social environment outside of the system but rather results from feedback within the system. The environment is not considered important for action. Nonetheless, action clearly proceeds and is significant to the rationale for the system.

The depiction of an information system presented in the Causeway example contains the idea that information is produced by the processing of data through set, planned methods and that the data will have the qualities noted above. In this sense the Causeway system is clearly an information system in accordance with traditional definitions that look for data, processing and feedback.

However, in presenting this case, our aim is to consider whether it exhibits universal qualities that allow it to be compared to routine, manual systems and whether there are common characteristics to be found in both types of systems. Can what appears in Causeway as data being processed to produce output and the resultant feedback leading to activity, be found to have some shared qualities with the features of routine, manual systems?

\section{Routine, manual systems}

A description of three routine, manual systems is presented below. 


\section{Emergency ambulance dispatch}

An Emergency dispatch system for ambulances is described by Wong and Blandford (Wong, 2000; Wong and Blandford, 2001; Wong and Blandford, 2004). Emergency dispatch occurs in a difficult and changing context where it is essential to the process that operators are aware of the goings-on in and around the area being covered by the ambulances and are aware of the capabilities of ambulance control to respond to possible eventualities. The system is divided into two functional areas: call taking and prioritisation; and command and control of emergency ambulances. There is a single control room where radio operators sit on one side and dispatchers on the other. The call takers (allocators) sit in the middle.

The activity begins when calls for ambulances are received by a call taker and are keyed into a Computer Assisted Design system. This system produces a printed ticket that includes details such as the type of emergency, address of the emergency, the priority of the condition (e.g. a heart attack has priority over a broken leg) and a map reference. From this point, the system becomes manual as tickets are first handed to a telephone dispatcher who contacts an ambulance crew at the station and dispatches it, and then to a radio operator who stays in touch with the ambulances on the road.

Once the ticket is printed any status changes, such as whether or not the ambulance is on the way or has arrived, are recorded by hand on the ticket. However, these can also be indicated by where the ticket is placed on the allocator's desk or by how the ticket is placed in the allocator's box since:

management of tickets centres around the 'allocator's box'. This is a slotted metal box with each slot corresponding to a vehicle in the sector. The ticket assigned to a vehicle, representing the job to which it is currently assigned, is kept in the relevant slot. The ticket faces forward while the vehicle is on the call, and is reversed when the vehicle is returning to the station but available for dispatch. The box sits between the allocator and radio operator, where either may easily access it (Blandford et al., 2002).

In deciding which ambulance to dispatch, allocators often use cues from the placement and positioning of the tickets rather than the written information contained thereon.

\section{Air traffic control}

Airports have traditionally used a largely manual system for air traffic control (Mackay, et al., 1998). The system is still respected and used in many places, and has longevity despite the drive for high-tech solutions in many airports. 
The activity of landing a flight begins with a printed, paper flight strip containing a small area to record basic flight plan information. This includes 'airline, flight number and type of aircraft as well as the requested and authorised flight plan (speed, level, route, with expected times for particular cross points)' ( Mackay et al., 1998). The system is routine and has an air traffic controller seated in front of a table of such strips. The strips are generated either by computer or can be hand-written in the absence of a working computer system.

Each airport has several air traffic controllers controlling different parts of the air space around the airport. The controller's first task in the system is to remove the flight strip from the printer and insert it into a strip holder. Strips are continually picked up and put down, reordered, grouped, moved into columns, arranged and rearranged on the controller's table to denote different traffic conditions. Strips are often offset. Offsetting provides a fast way of 'indicating conflicts or setting reminders' (Mackay, 1999). The placement of the strips in various configurations in relation to each other provides the controllers with information regarding action additional to what is written on the strips.

Once a controller takes control of a flight strip the controller gradually adds markings to the typed strip. The markings allow controllers to look at a group of flight strips and quickly select the ones coming under their control as well as giving other information about how the activity is progressing. The layout of strips also gives a controller an immediate appreciation of the control situation (involving many flights), thus helping the controller to select the next action. For example, a controller can see at a glance that a strip holder is full, and can also see the strip holders of adjacent controllers and monitor their activities without interrupting them. As the landing progresses the flight strip passes from one controller to another by physical handover that by its nature is palpable for both controllers. Often controllers are side-by-side, thus facilitating handover to another sector by structuring the area to help the activity.

\section{ICU ward management system}

Our third routine manual system is in the intensive care unit (ICU) of a 360-390-bed acute tertiary referral hospital. The intensive care unit has 24 beds, including 20 Intensive Care beds and four High Dependency beds

The system is a resource allocation system that monitors the movement in and out of the ward, and condition, of ICU patients. The goal of the system is to allocate beds as well as to manage movement in and out of beds in the short term.

The utilisation of beds is recorded on a whiteboard, which operates in the highly dynamic environment of a busy public hospital with a constantly operating admissions procedure presenting patients to the system. The whiteboard displays a picture of the bed cubicles, some or all of which may be occupied by patients, 
and a set of artifacts including magnets and stickers that indicate and describe bed usage. The board is located in a central position in full view of the beds that it depicts. It is positioned in such a way that it can be viewed simultaneously by a number of staff.

The board is designed with a large rectangle in the middle representing the nurses' station and with blank rectangles drawn around it corresponding to the position of each bed relative to the nurses station. There are 24 positions on the board, each representing one cubicle, and a set of magnetic name cards that can have patient names written on them. These name cards are erasable and re-usable. The name written on a magnetic card placed on rectangle 21, for example, corresponds to the patient in bed 21. Patient names are written on the name cards with coloured markers. A name written in blue marker is a cardiac patient and a name written in black marker can be any other non-cardiac patient.

In addition to the name labels there are coloured plastic magnets in groups at the top of the board. These can be taken and placed on particular bed cubicles on the whiteboard. An orange magnet means possible discharge from ICU, a green magnet means definite discharge, a red magnet means incoming patient, and yellow means the patient will receive no further treatment. Patients with red magnets may not have yet been allocated a bed but may be placed on a name sticker set to the side of the board. If a bed is allocated, the name sticker may be half on and half off the designated cubicle.

Users of the board, having different functions such as doctor, nurse, physiotherapist or chaplain within the ward, gather around the board to respond, both collectively and individually, to what it displays. Colours such as the blue for a cardiac patient allow a cardio-thoracic physiotherapist, for example, to instantly carve off her/his list of patients; many green magnets, designating patients ready for discharge from ICU, tells the managing nurse to start finding beds in the general wards; many yellow magnets for palliating patients tells the chaplain to prepare for many families requiring support. The ease with which the magnets can be picked up and swapped around facilitates formulating the solutions to many of the problems being addressed and redesigning patient discharge scenarios.

\section{Qualities of routine, manual systems}

In these routine, manual systems elements manifest themselves in a very different way to that described in conventional information systems such as Causeway. In these systems the following qualities, which have been previously attributed to 'situated' systems (Lederman, et al., 2003), are evident where participants focus on 'situations' that only include features of the world that relate to the participants' purposes (Agre, 1997). For example, a system participant might be 
interested in how much stock they could see on a shelf at this moment and the specific meaning that conveys to the participant concerned.

In routine, manual systems:

- Representations depend on the situation in which they are used. So, for example, a card in an ambulance dispatch system may have a different meaning when placed one way in a dispatch box than when placed another way. These different meanings signal the need to manipulate other system elements and generate a response from the system that tells participants how to act.

- Situations relevant to goal attainment can be represented temporarily when they are transitory. So, for example, a whiteboard for bed management in a hospital ward may use coloured magnets to express a situation where a patient 'may' be discharged. We see this in the ICU ward with an orange magnet, or sometimes two orange magnets to say, 'maybe, maybe'. The data expressed is not binary — where a patient is either ready for discharge or not - but an aspect of a changing and transitory situation. The data is not crisp or permanent but is instead fuzzy. Yet it has a valuable place in indicating a need for some development, such as a bed re-allocation, to take place that transforms the state of the system.

- Situations are triggers for reactive rule-like responses. In such systems, situations can be perceived directly. This direct perception can be considered akin to processing, but does not require reading or significant cognitive activity where rules have previously been learnt. Consequently, a development in the system occurs where actors respond automatically to the positioning of items, such as tickets laid out on a desk or different coloured magnets placed on a whiteboard. This leads to further changes in the situation at hand, with such changes being part of the rationale for such systems. That is, these triggers manifest themselves to inform action, to tell participants what to do next.

- The structuring of the social and physical environment of the system is important. In typical information systems all the data required is contained within databases or files that form predefined components of the system and the outside environment is of minimal importance. In these systems, however, aspects of the environment contain cues that are instrumental in triggering activity leading to consequent transformation within the system. So, for example, in the air traffic system a number of controllers grouped together talking intently can tell another controller that there is a problem requiring action. What leads to a response or action is separate from the actual information written on the flight strips. Rather, situations such as the placement of the strips, the arrangement of people in the room, or the number of strips in the strip board is significant for action. Because of this, these 
systems have evolved in ways that facilitate the inclusion of such factors with rooms designed, for example, in ways that system participants can see and take advantage of available cues.

These three systems, while very different to the Causeway system contain many situations that signal the need for action. These situations occur and are developed in some way through the manipulations of system participants, with these new developments promoting further responses. The term development is used here to refer to a stage of growth or advancement (Australian Oxford Dictionary) where a practice is made active by successive changes (Webster's Dictionary). Whereas processing is present in traditional systems, in these systems situation development is observed directly and leads to a subsequent response from system participants. So, for example, where an extra magnet is added to the ICU whiteboard there is a growth in the information value of the board in the same way that processing traditional data in a spreadsheet is said to produce information. Such changes, or developments, activate the new situation in a way that encourages response. However, while these systems are characterised by 'situation, development of situation, new situation, response' whereas in traditional systems it is 'data, processing of data, output, feedback' we suggest that these differences may be superficial. In the next sections we consider whether there are qualities in both types of systems that are universal and make it possible to unite all systems under a common definition.

\section{Are all these systems information systems?}

It has been suggested earlier in this paper that for a system to be considered an information system it needs to demonstrate that it contains facts that can be manipulated in ways that change or transform the state of the system. This transformation then results in a signal that functions as an alert and triggers a response or feedback action. This resulting action maintains the dynamism of the system and occurs where informational aspects of the system are relevant to participants' goals. These four elements, fact, transformation, signal, and action are required for the label 'information system' to be applied. This section will look at the narrative that has been provided about each of the four systems and the qualities extracted from them and reflect on whether or not the required indicators are present. We attempt to extract the overarching concepts that encompass the qualities of both types of systems; qualities that include elements that are like data and like processing and like output and like feedback yet are also understandable in the context of non-traditional systems.

\section{Fact: the first universal element}

Looking at both types of systems, it is observed that the basic elements of both the traditional system and the routine manual system have the characteristics of facts. In both types of systems elements stand for something within the 
community of the system. In the traditional system there is a credit limit in a table of customers, in the manual routine system there is the manner in which cards are placed in an allocation box. Both elements stand for something as well as establishing a rule determining how the element is understood. While the elements in the traditional system are easily called data, in the non-traditional system using the term data, which has previously been more closely associated with numbers, words, symbols or events, creates expectations of something different in the situations encountered. Facts however, can be understood as observable objects or events (Checkland and Howell, 1998) or even 'a situation that exists' (Oxford English Dictionary). In this, the term fact can include the data found in traditional systems or the situations found in routine, manual systems.

\section{Transformation: the second universal element}

Traditional information systems are said to contain data, which is then processed. In processing, data is altered by first selecting it and then in some way organising, manipulating or aggregating it. In a system like Causeway, data such as an invoice amount is selected in a deliberative manner from an invoice. The data is then inserted into the accounts receivable master file, which is updated. Thus, traditional numeric data is processed.

In routine manual systems, a course of action that is both similar and different to processing in traditional systems occurs. A situation in a system, such as the existence of a coloured magnet on a whiteboard, is perceived directly by a user and the user reacts by, for example, instigating a development such as moving the magnet to a different place on the whiteboard. At the end of this activity the board reflects a newly developed situation, not dissimilar to the updating of a master file, and further response can occur. While what happens to the whiteboard may not commonly be seen as processing, what is common to the two systems is the idea of transformation discussed earlier from the systems literature (Land, 1973), and also referred to in the semiotics literature (e.g. Liu, 2000). Transformation occurs when systems participants are faced with cues from their environment, which may be data or situations, and the participants then define and redefine what to do next, either processing data or developing a situation, altering the system each time to transform it to a state closer to the participants' goal or objective. When a fact from either type of system is presented for manipulation, a transformation can occur. Thus, transformation is common to both types of systems.

\section{Signal: the third universal element}

As stated previously a conventional understanding of output includes the kind of elements, such as customer information, cheque totals, and credit listings, seen in the Causeway system. It does not traditionally include elements such as 
the way a ticket is placed on a table, the busyness of a room, or the emptiness of a slot on a whiteboard. However, earlier in this paper output was also described as something that signals or projects processed facts. Based on this description, semiotics provides a possible bridge across both types of systems. It is argued that elements within systems transfer messages (signs or signals) and that this communication results in action based on the transferred sign. A sign is defined as 'anything that conveys information because it stands for something else within a community' (Stamper, 2001). The role of a sign 'is to establish a habit or general rule determining ... the way the sign is to be "understood" on the occasions of its use' (MacEachren, 1995).

What unifies the elements of both types of system is the appropriateness of the application to each of the term sign, or its further extension from the semiotics literature, signal. According to MacEachren (1995) 'when a sign token mechanically or conventionally triggers some reaction on the part of the receiver, it is said to function as a signal'. Signals are seen as containing 'pragmatic information' (Stamper, 2001) that has the potential to change action and, in this sense, 'signal' is a more appropriate term for what is evident in a dynamic system than is 'sign'.

Stamper (2001) suggests that actors learn to employ particular repertoires of behaviour and that particular signals come to stand for these repertoires. In the ICU Ward Management Case, for example, a coloured magnet of a particular kind might come to trigger a particular repertoire. In systems where concepts are perspectival, behaviours are triggered for individuals who process the information in a way that is significant to them. Similarly, the representation of situations that may be transitory provides a signal that assists in the navigation of a changing environment. A magnet indicating or signalling that a patient may be discharged creates a cue to initiate or prepare for action. Additionally, situations that no traditional interpretation of what constitutes an information system would consider to be output, such as the phenomenon of ATC controllers gathered round a table, can be seen as signals that can be transformed into information for action. These new situations that occur following the transformation of previous situations, signal action in the same way that a credit limit in a database provides a signal that can be acted upon.

In routine, manual systems whole situations with multiple aspects may be significant as signals. For example, the way a flight strip is placed is interpreted within the context of a flight strip holder, which is in turn interpreted within the context of a room full of flight controllers. In traditional systems, conversely, output is abstracted and de-contextualised and the importance of the broader context outside of a particular table or database is marginal. However, while the form and breadth of representation in both types of system are different, they are similar in providing a signal for action. Thus, the term signal is a term that 
encompasses both the output of traditional systems and the new situations, following previous situation development, found in routine, manual systems.

\section{Action: the fourth universal element}

Finally, the response to, or feedback resulting from, the signals in both types of systems provides the fourth element of an information system: an impetus for action. In all systems the signals produced provide the cues for action necessary to keep the system functioning as a goal attaining entity. In Causeway, for example, processed data brings the database to a new state providing the feedback for the next activity. In the ICU ward, for example, a situation indicating possible availability of a patient for transfer is developed into a new situation, a definite availability evoking a response from a staff member. In the two types of systems what happens after the signal is apparent is different. In traditional systems, output generally provokes a cognitive response, based on the information the new state provides. That is, the original data is manipulated in some way and the user thinks about the result of processing (the output) before acting. In the routine, manual systems, new situations are often perceived much more directly (Lederman et al., 2003) in the sense that a movement of a coloured magnet on a whiteboard is detected and responded to in a way that is largely reactive and non-cognitive, and quite different from the deliberative reading of a new value in a table. However, whether the fourth stage is a traditional cognitively based or a reactive response, both eventualities correspond to action, the fourth common feature of the two types of system. Thus action is a unifying feature found in both types of systems following the initial three elements.

\section{The universal features of information systems}

These ideas are expressed in Table 2 below, which provides the values missing in Table 1. Table 2 expresses what is common in both types of systems and unifies these common elements under a larger, universal heading. Where there is data input, such as a cheque amount in a traditional system, in a routine, manual system the input is a situation that occurs, such as a magnet placed on a board. Both of these elements provide facts to enter into the next stage in the system. In a traditional system the data is processed by, for example, adding or multiplying whereas in a routine manual system it is developed in some way that augments or diminishes its meaning such as moving the magnet across the board. In all cases a transformation occurs where the state of the system is now changed. In traditional systems this changed state is represented as output; in routine, manual systems it is represented as a new situation. However, in both cases what is evident is a signal for action by users. Finally, in the traditional system an item of data output such as a cheque total produces an action such as a confirmation of the total. Similarly in the routine, manual system the new 
situation cues a response such as a rearrangement of other magnets or a review of bed allocations. Both feedback and response are unified in the impetus for action that they provide.

Reviewing Table 2 our claim is that all of the systems discussed above exhibit the qualities of information systems. While the difference between the system elements are analytical in routine manual systems rather than clearly separated in space and time in the way that making a change in a database and producing a new report might be in a traditional system, a unified view of both types of systems can still be presented. It may be harder to identify an element such as an output in a routine, manual system than in a traditional system. However our claim is that such elements, although having a different form, have universal qualities that can be found and aligned across both types of systems. These universal elements include facts and transformation, which encompass the traditional concepts of information systems, data and processing, as well as the situations and situation development found in routine, manual systems. When transformation occurs a change in the system takes place creating data output or the evolution of a new situation. This elicits action and moves the system one step closer to goal fulfilment. Fundamentally, what makes a system an information system is the existence of four things: facts that can be transformed by users into signals which promote action. Thus, we argue that through these shared features all of these systems can rightfully take the same label: information system.

\begin{tabular}{|c|c|c|c|c|c|c|c|c|}
\hline & Fact & & Transforma & tion & Signal & & Action & \\
\hline & $\begin{array}{l}\text { Traditional } \\
\text { Data }\end{array}$ & $\begin{array}{l}\text { Routine } \\
\text { Situation }\end{array}$ & $\begin{array}{l}\text { Traditional } \\
\text { Process }\end{array}$ & $\begin{array}{l}\text { Routine } \\
\text { Development }\end{array}$ & $\begin{array}{l}\text { Traditional } \\
\text { Output }\end{array}$ & $\begin{array}{l}\text { Routine } \\
\text { New } \\
\text { Situation }\end{array}$ & $\begin{array}{l}\text { Traditional } \\
\text { Feedback }\end{array}$ & $\begin{array}{l}\text { Routine } \\
\text { Response }\end{array}$ \\
\hline Examples & $\begin{array}{l}\text { Cheque } \\
\text { amount } \\
\text { Invoice } \\
\text { total } \\
\text { Customer } \\
\text { total owed }\end{array}$ & $\begin{array}{l}\text { Coloured } \\
\text { magnet on } \\
\text { a board } \\
\text { Placement } \\
\text { of a flight } \\
\text { strip on a } \\
\text { table } \\
\text { Position of } \\
\text { a card in } \\
\text { allocation } \\
\text { box }\end{array}$ & $\begin{array}{l}\text { Totalling of } \\
\text { cheques } \\
\text { Verifying } \\
\text { amount on } \\
\text { invoice } \\
\text { Summanising } \\
\text { customer } \\
\text { accounts }\end{array}$ & $\begin{array}{l}\text { Movement } \\
\text { of a } \\
\text { magnet } \\
\text { Re-ordering } \\
\text { of a flight } \\
\text { strip on a } \\
\text { table } \\
\text { Turning of } \\
\text { a card in } \\
\text { allocation } \\
\text { box }\end{array}$ & $\begin{array}{l}\text { New } \\
\text { Cheque } \\
\text { total } \\
\text { New } \\
\text { invoice } \\
\text { total } \\
\text { New } \\
\text { Customer } \\
\text { total }\end{array}$ & $\begin{array}{l}\text { Whiteboard } \\
\text { changed } \\
\text { Rearranged } \\
\text { flight strip } \\
\text { Repositioned } \\
\text { Ambulance } \\
\text { ticket }\end{array}$ & $\begin{array}{l}\text { Compare } \\
\text { totals } \\
\text { Confirm } \\
\text { totals } \\
\text { Confirm } \\
\text { summary }\end{array}$ & $\begin{array}{l}\text { Review } \\
\text { bed } \\
\text { allocations } \\
\text { Attend to } \\
\text { flight } \\
\text { descent } \\
\text { Reallocate } \\
\text { ambulance }\end{array}$ \\
\hline
\end{tabular}

Table 2: Elements in all information systems

\section{Conclusion}

The four systems described here illustrate the qualities required to make a system deserving of the appellation 'information system'. We have shown that while the hallmarks of traditional systems, data, processing, output and feedback may not be obvious in some non-traditional systems, using a wider terminology allows systems with apparently quite different qualities to be included under a 
broader definition of IS. Adopting the terms signal and transformation, taken from the general systems and semiotics literature, and adding the concept of action, we have proposed a common terminology that legitimises the label information system not just for traditional systems but also for the routine manual systems described. This approach makes a novel contribution to the IS literature and will assist IS researchers in classifying a wide variety of systems as within or outside the information systems category.

\section{References}

Agre, P. 1997, Computation and Human Experience, New York, Cambridge University Press.

Benson, S. and Standing, C. 2002, Information Systems: A Business Approach, John Wiley and Sons.

Boddy, D., Boonnstra, A. and Kennedy, G. 2005, Managing Information Systems, Pearson.

Checkland, P. and Howell, S. 1998, Information, Systems, and Information Systems, Chichester: John Wiley and Sons.

Donde, P. A. and Huber, G. P. 1987, 'The systems paradigm in organisation theory: Correcting the record and suggesting the future', The Academy of Management Journal, vol. 12, no. 4, pp. 607-21.

Galland, F. J. 1982, Dictionary of Computing, Chichester: John Wiley and Sons.

Gelinas, U. and Sutton, S. 2002, Accounting Information Systems, Cincinnati, Thomson Learning.

Goldkuhl, G. and Agerfalk, P. 1988, 'Action within information systems: An outline of a requirements engineering method', Proceedings 4th International Workshop on Requirements Engineering: Foundation for Software Quality, Pisa, Italy.

Goldkuhl, G. and Agerfalk, P. 2000, 'Actability: A way to understand information systems pragmatics', Proceedings of the Third International Workshop on Organisational Semiotics, Staffordshire, UK.

Hicks, J. O. 1993, Management Information Systems: A User Perspective, Minneapolis, West Publishing.

Land, F. 1987, 'Adapting to changing user requirements', in Galliers, R. (ed.), Information Analysis: Selected Readings, Addison-Wesley, pp. 203-35.

Land, G. 1973, Grow or Die: The Unifying Principle of Transformation, Random House.

Laudon, K. and Laudon, J. 2006, Management Information Systems, 9th ed., New Jersey: Pearson/Prentice Hall. 
Lederman, R., Johnston, R. and Milton, S. 2003, 'The significance of routines for the analysis and design of information systems', Proceedings of the European Conference in Information Systems, Naples, Italy.

Liu, K. 2000, Semiotics in Information Systems Engineering, Cambridge University Press.

MacEachren, A. M. 1995, How Maps Work, New York, The Guildford Press. Mackay, W. 1999, 'Is paper safer? The role of paper flight strips in Air Traffic Control', ACM Transactions on Computer-Human Interaction, vol. 6, no. 4, pp. 311-40.

Mackay, W. E., Fayard, A.-L., Frobert, L. and Medini, L. 1998, 'Reinventing the familiar: Exploring and augmented reality design space for Air Traffic Control', Proceedings of Computer Human Interation (CHI'98), Los Angeles, CA.

Maddison, R. 1989, Information Systems Development for Managers, London, Paradigm.

Martin, C. and Powell, P. 1992, Information Systems: A Management Perspective, London, McGraw-Hill.

O'Brien, J. 2003, Introduction to Information Systems, Boston, McGraw-Hill Irwin.

Schmidt, K. and Simone, C. 1996, 'Coordination mechanisms: Towards a conceptual foundation of CSCW systems design', The Journal of Collaborative Computing, vol. 5, pp. 155-200.

Stair, R. and Reynolds, G. 2003, Principles of Information Systems, 6th ed., Boston, MA, Thomson Course Technology.

Stamper, R. 2001, 'Organisational semiotics: Informatics without the computer', in Lui, K., Clarke, R., Andersen, P. and Stamper, R. (eds), Information, Organisation and Technology: Studies in Organisational Semiotics, Boston, Kluwer Academic.

von Bertalanffy, L. 1972, 'The history and status of General Systems Theory', The Academy of Management Journal, vol. 15, no. 4, pp. 407-26.

Wand, Y. and Weber, R. 1995, 'On the deep structure of information systems', Information Systems Journal, vol. 5, no. 3, pp. 203-23.

Wong, W. 2000, 'The integrated decision model in Emergency Dispatch Management and its implications for design', Australian Journal of Information Systems, vol. 2, no. 7, pp. 95-101.

Wong, W. and Blandford, A. 2001, 'Situation awareness and its implications for human computer interaction', Proceedings of the Australian Conference on Computer Human Interaction OzCHI 2001, Perth. 
Information Systems Foundations

Wong, W. and Blandford, A. 2004, 'Information Handling in Dynamic Decision Making Environments', Proceedings of the 12th European Conference on Cognitive Ergonomics, York. 